\title{
Potencial de hibridação entre acessos de tomateiro para pré-melhoramento quanto à resistência à requeima
}

\author{
Bruno Soares Laurindo(1), Renata Dias Freitas Laurindo(1), Carlos Nick(1), Pedro Crescêncio Souza Carneiro(2), \\ Eduardo Seiti Gomide Mizubuti( ${ }^{(3)}$ e Derly José Henriques da Silva ${ }^{(1)}$
}

\begin{abstract}
(1)Universidade Federal de Viçosa (UFV), Departamento de Fitotecnia, Avenida Peter Henry Rolfs, s/no , Campus Universitário, CEP $36570-900$ Viçosa, MG, Brasil. E-mail: brunosoareslaurindo@gmail.com, renataufv08@gmail.com, carlos.nick@yahoo.com.br, derly@ufv.br (2)UFV, Departamento de Biologia Geral, Avenida Peter Henry Rolfs, s/no, Campus Universitário, CEP 36570-900 Viçosa, MG, Brasil. E-mail: carneiro@ufv.br (3)UFV, Departamento de Fitopatologia, Avenida Peter Henry Rolfs, s/nº, Campus Universitário, CEP 36570-900 Viçosa, MG, Brasil. E-mail: mizubuti@ufv.br
\end{abstract}

Resumo - O objetivo deste trabalho foi avaliar genitores com potencial de hibridação para o pré-melhoramento do tomateiro (Solanum lycopersicum) quanto à resistência à requeima. Foram utilizados seis acessos de tomateiro (BGH-2102, BGH-2117, BGH-2127, BGH-2130, BGH-2332 e BGH-2343) como genitores resistentes e 15 híbridos $\mathrm{F}_{1}$ originários destes genitores. Utilizou-se o delineamento de blocos ao acaso, com três repetições. As plantas foram inoculadas com uma mistura de esporângios de Phytophthora infestans, agente etiológico da requeima, na concentração de $5 \times 10^{3}$ esporângios $\mathrm{mL}^{-1}$. A área abaixo da curva de progresso da doença foi utilizada para avaliar a resistência. Realizou-se a análise dialélica, tendo-se considerado o efeito de genótipos como fixo. Estimou-se a capacidade geral e específica de combinação dos acessos. O padrão de resistência dos genitores e da maioria dos $\mathrm{F}_{1}$ foi o mesmo que o das testemunhas resistentes. Foram observados: variabilidade genética aditiva entre os genitores, predominância de efeitos gênicos não aditivos e desvios de dominância bidirecional no controle do caráter. A frequência de alelos favoráveis e divergentes para resistência à requeima é maior nos acessos BGH-2117, BGH-2127 e BGH-2343.

Termos para indexação: Phytophthora infestans, Solanum lycopersicum, capacidade combinatória, fonte de resistência.

\section{Hybridization potential among tomato accessions for pre-breeding for resistance to late blight}

\begin{abstract}
The objective of this work was to evaluate parents with hybridization potential for pre-breeding of tomato (Solanum lycopersicum) for resistance to late blight. Six tomato accessions (BGH-2102, BGH-2117, BGH-2127, BGH-2130, BGH-2332, and BGH-2343) were used as resistant parents and $15 \mathrm{~F}_{1}$ hybrids originated from these parents. The design was a randomized complete block with three replicates. The plants were inoculated with a mixture of Phytophthora infestans sporangia, the etiological agent of late blight, at a concentration of $5 \times 10^{3}$ sporangia $\mathrm{mL}^{-1}$. The area under the disease progress curve was used to evaluate resistance. Diallelic analysis was performed, considering the effect of genotypes as fixed. The general and specific combining ability of the accessions was estimated. The resistance pattern of the parents and of most of the $F_{1}$ was the same as that of the resistant controls. The following were observed: additive genetic variability among the parents, predominance of nonadditive gene effects, and bidirectional dominance deviations in the control of the trait. The frequency of favorable and divergent alleles for late blight resistance is higher in the BGH-2117, BGH-2127, and BGH-2343 accessions.
\end{abstract}

Index terms: Phytophthora infestans, Solanum lycopersicum, combining capacity, source of resistance.

\section{Introdução}

O oomiceto Phytophthora infestans (Mont.) de Bary, agente etiológico da requeima, é um dos patógenos mais destrutivos do tomateiro (Solanum lycopersicum L.) cultivado, o que resulta em perdas significativas na cultura (Nowicki et al., 2012). Atualmente, a maioria das cultivares de tomateiro é suscetível à requeima, e o manejo da doença é realizado principalmente por meio da aplicação de fungicidas (Foolad et al., 2014).

Os genes $P h-1, P h-2$ e $P h-3$, situados nos cromossomos 7, 10 e 9, respectivamente, da espécie 
silvestre de tomateiro Solanum pimpinellifolium L. conferem resistência qualitativa à requeima (Nowick et al., 2012). No entanto, há relatos que isolados de $P$. infestans suplantaram a resistência conferida por esses genes (Miranda et al., 2010), o que mostra que os programas de melhoramento genético do tomateiro devem buscar outros mecanismos que incorporem a resistência do tipo quantitativa (Elsayed et al., 2011).

O pré-melhoramento mostra-se como alternativa viável para esse fim. Dessa forma, a busca por recursos genéticos que possam ser usados como fonte de resistência à requeima tem sido realizada no Banco de Germoplasma de Hortaliças da Universidade Federal de Viçosa (Abreu et al., 2008; Fiorini et al., 2010; Elsayed et al., 2011; Nick et al., 2013).

A resistência à requeima foi identificada nas espécies silvestres Solanum habrochaites S.Knapp \& D.M. Spooner(Abreu et al., 2008) e Solanum pimpinellifolium (Foolad et al., 2014). Contudo, quando as fontes são da mesma espécie que se deseja melhorar, há maior facilidade de cruzamentos para transferência de genes (Abreu et al., 2008) e recuperação mais rápida das características agronômicas desejadas (Adalid et al., 2012). Nesse contexto, a busca por fontes de resistência em acessos pertencentes à espécie $S$. lycopersicum é desejável.

Cruzamentos intra e interespecíficos são utilizados no desenvolvimento de cultivares híbridas de tomateiro que sejam competitivas e resistentes à requeima. Para isso, os genitores precisam ser genotipicamente divergentes, além de apresentarem elevada frequência dos alelos de resistência à requeima. A divergência genética tem sido quantificada por meio de técnicas biométricas e por processos preditivos. Entre os métodos fundamentados em modelos biométricos que se destinam à quantificação da divergência dos genitores, destacam-se os dialelos, que permitem estimar tanto a capacidade geral quanto a capacidade específica de combinação dos genitores (Cruz et al., 2012).

O objetivo deste trabalho foi avaliar genitores com potencial de hibridação para o pré-melhoramento do tomateiro (Solanum lycopersicum) quanto à resistência à requeima.

\section{Material e Métodos}

O trabalho foi conduzido no campo experimental do setor de olericultura da Universidade Federal de Viçosa
(UFV), em Viçosa, MG (2045'14"S, 42 ${ }^{\circ} 52^{\prime} 53^{\prime \prime} \mathrm{W}$, a 648,74 $\mathrm{m}$ de altitude).

Para a obtenção dos híbridos experimentais, foram utilizados como genitores seis acessos de $S$. lycopersicum: BGH-2102, BGH-2117, BGH-2127, BGH-2130, BGH-2332 e BGH-2343, previamente selecionados como resistentes à requeima entre os 192 acessos avaliados preliminarmente. Estes acessos encontram-se conservados no Banco de Germoplasma de Hortaliças da Universidade Federal de Viçosa (BGH-UFV).

Após a obtenção das sementes provenientes dos cruzamentos, os seis acessos de S. lycopersicum e os 15 híbridos $F_{1}$, originados do cruzamento entre estes acessos, foram avaliados quanto à resistência à requeima. Utilizaram-se como testemunhas resistentes à requeima o acesso BGH-6902 (Abreu et al., 2008) e as linhagens 133 A e 163 A (Fiorini et al., 2010), originadas do cruzamento interespecífico entre a cultivar Santa Clara (S. lycopersicum) e o acesso BGH-6902 (S. habrochaites). Como padrão de suscetibilidade, foram utilizadas as cultivares Débora, Fanny e Santa Clara.

Utilizou-se o delineamento de blocos ao acaso, com três repetições e cinco plantas por parcela, e a parcela útil foi constituída pelas três plantas centrais.

A semeadura foi realizada em bandejas de 128 células, que continham substrato comercial para hortaliças, e o transplantio para o campo foi feito quando as plantas apresentavam quatro folhas definitivas, no espaçamento de $1,0 \times 0,5 \mathrm{~m}$. As plantas foram conduzidas com uma única haste e tutoradas com fitilho na vertical. Os tratos culturais foram realizados de acordo com o recomendado para a cultura (Guimarães et al., 2007). A utilização de defensivos agrícolas foi suspensa 15 dias antes da inoculação e durante as avaliações para resistência à requeima.

A coleta, o preparo e a inoculação dos isolados de $P$. infestans foram realizados seguindo o método de Abreu et al. (2008), com algumas modificações.

Quarenta e cinco dias após o transplantio, as plantas foram submetidas à inoculação com uma mistura de esporângios provenientes de isolados de $P$. infestans, patogênicos ao tomateiro, que foram coletados em diferentes regiões da Zona da Mata Mineira, nos municípios de Cajuri, Coimbra, Ervália e Viçosa. Esse procedimento foi realizado para agregar maior número de variantes possíveis de resistência qualitativa. 
Nos locais de coleta, foram retirados das plantas folíolos infectados por $P$. infestans, que foram colocados dentro de sacos de papel de $1,0 \mathrm{~kg}$, previamente identificados com o nome do município em que foi realizada a coleta, e armazenados em caixas de isopor a $18^{\circ} \mathrm{C}$. O inóculo foi multiplicado no Laboratório de Manejo de Recursos Genéticos da UFV. Para isso, transferiram-se os folíolos dos sacos de papel para bandejas de plástico previamente desinfetadas com álcool a $70 \%$ e forradas com papel toalha umedecido com água destilada, mantidas a $18^{\circ} \mathrm{C}$ por 24 a 48 horas, de modo a criar um microclima favorável ao desenvolvimento do patógeno e promover maior esporulação.

Após esse período, para cada isolado, foi preparada uma suspensão de esporângios, que foi homogeneizada, tendo-se realizado a contagem do número de esporângios em microscópio óptico. Em seguida, ajustou-se a concentração em hemacitômetro para $5 \times 10^{3}$ esporângios $\mathrm{mL}^{-1}$. Após a contagem do número de esporângios, a suspensão foi levada à geladeira por 1 hora, para estimular a liberação de zoósporos. A inoculação ocorreu em 7 de maio de 2012, por volta das $18 \mathrm{~h} 00$, com o auxílio de pulverizador costal manual, tendo-se aplicado $10 \mathrm{~mL}$ de suspensão por planta. O tempo decorrido entre o preparo da suspensão de esporângios e a inoculação não excedeu 2 horas, para que os zoósporos permanecessem viáveis. No dia posterior à inoculação, para garantir alta umidade ao ambiente, as plantas passaram a ser irrigadas por aspersão.

Três dias após a inoculação, iniciaram-se as avaliações quanto à severidade da requeima, realizadas entre 10 e 25 de maio de 2012, em intervalos regulares de 3 dias, o que totalizou seis avaliações. No período compreendido entre a inoculação e as avaliações, no município de Viçosa, MG, foram detectadas temperaturas médias máxima e mínima de $22,7^{\circ} \mathrm{C}$ e $13,8^{\circ} \mathrm{C}$, respectivamente. A umidade relativa média foi de $86,2 \%$ e a precipitação foi de $73,8 \mathrm{~mm}$. Estas condições meteorológicas são consideradas adequadas para o desenvolvimento da requeima (Nowicki et al., 2013).

Nas avaliações de severidade da doença, utilizouse o programa Severity PRO (Nutter, 1997) para treinamento da equipe de avaliação, a fim de corrigir distorções inerentes à estimativa visual. No campo, foram atribuídas notas às folhas de cada planta, de acordo com escala diagramática proposta por Corrêa et al. (2009), para estimar a severidade da doença.

A nota final de cada planta foi constituída pela média das notas de suas folhas e posteriormente utilizada para estimar a área abaixo da curva de progresso da doença (AACPD), de acordo com Madden et al. (2007), por meio da expressão:

$$
\text { AACPD }=\left\{\sum_{i+1}^{n-1}\left[\left(y_{i}+y_{i+1}\right) / 2\right] \times\left(t_{i+1}-t_{i}\right)\right\}
$$

em que: $y_{i}$ e $y_{i+1}$ são a percentagem de área foliar lesionada observada na avaliação $i$ e na seguinte $i+1 ; t_{i}$ e $t_{i+1}$ são o intervalo de tempo entre as avaliações; e n é o número total de avaliações.

A seleção para resistência à requeima foi feita no sentido negativo, ou seja, quanto menor a AACPD maior o grau de resistência do indivíduo.

Os dados da AACPD foram submetidos à análise de variância, pelo teste $\mathrm{F}$, a $1 \%$ de probabilidade. As médias dos genitores e dos $F_{1}$ foram comparadas às médias das testemunhas por meio do teste de Dunnett, a $5 \%$ de probabilidade.

Também foi realizada análise dialélica, de acordo com o método 2, no qual se consideram os genitores e as $\mathrm{p}(\mathrm{p}+1) / 2$ combinações, e excluem-se os híbridos $\mathrm{F}_{1}$ recíprocos; e com o modelo 1 , no qual se considera o efeito de genótipos como fixo e estimamse os componentes quadráticos, que expressam a variabilidade genética do material estudado, em termos da capacidade geral e específica de combinação, como descrito em Griffing (1956).

As análises foram realizadas com auxílio do aplicativo computacional Genes (Universidade Federal de Viçosa, Viçosa, MG).

\section{Resultados e Discussão}

Foram observadas diferenças significativas em todas as fontes de variação quanto à $\mathrm{AACPD}$, o que denota variabilidade para a característica estudada entre os tratamentos.

O coeficiente de variação para a AACPD foi de $47,75 \%$ (Tabela 1). Resultados semelhantes foram encontrados por Nick et al. (2013), que avaliaram a resistência à requeima em progênies de tomateiro derivadas do cruzamento interespecífico entre $S$. licopersycum e a espécie silvestre $S$. habrochaites f. glabratum. Valores elevados de coeficiente de 
variação podem estar associados à elevada influência ambiental dessa característica, bem como às diferenças entre as taxas de progresso da doença e à dificuldade de homogeneidade nas notas atribuídas a um mesmo tratamento (Elsayed et al., 2011).

Tabela 1. Médias de área abaixo da curva de progresso da doença (AACPD), em resposta à requeima causada por Phytophthora infestans, de seis genitores, 15 híbridos, três testemunhas resistentes (BGH-6902, 133 A e 163 A) e três testemunhas suscetíveis (Débora, Fanny e Santa Clara) de tomateiro (Solanum spp.), considerados como tratamento ${ }^{(1)}$.

\begin{tabular}{lc}
\hline Tratamento & Médias de AACPD \\
\hline BGH-2332 x BGH-2102 & $249,75 \mathrm{c}$ \\
BGH-2332 & $199,37 \mathrm{f}$ \\
BGH-2117 x BGH-2102 & $189,27 \mathrm{ef}$ \\
BGH-2332 x BGH-2130 & $140,20 \mathrm{def}$ \\
BGH-2343 x BGH-2332 & $139,67 \mathrm{def}$ \\
BGH-2343 x BGH-2102 & $120,24 \mathrm{def}$ \\
BGH-2343 & $95,75 \mathrm{def}$ \\
BGH-2343 x BGH-2117 & $91,32 \mathrm{def}$ \\
BGH-2130 x BGH-2117 & $88,90 \mathrm{def}$ \\
BGH-2102 & $86,89 \mathrm{def}$ \\
BGH-2332 x BGH-2127 & $80,54 \mathrm{def}$ \\
BGH-2127 & $79,02 \mathrm{def}$ \\
BGH-2332 x BGH-2117 & $78,52 \mathrm{def}$ \\
BGH-2117 & $64,37 \mathrm{def}$ \\
BGH-2130 & $61,61 \mathrm{def}$ \\
BGH-2127 x BGH-2117 & $61,14 \mathrm{def}$ \\
BGH-2130 x BGH-2127 & $58,68 \mathrm{def}$ \\
BGH-2127 x BGH-2102 & $55,96 \mathrm{def}$ \\
BGH-2127 x BGH-2343 & $52,39 \mathrm{def}$ \\
BGH-2130 x BGH-2102 & $48,43 \mathrm{def}$ \\
BGH-2343 x BGH-2130 & $47,90 \mathrm{def}$ \\
Débora & $452,57 \mathrm{a}$ \\
Fanny & $421,12 \mathrm{~b}$ \\
Banta Clara & $362,15 \mathrm{c}$ \\
133 A & $24,86 \mathrm{~d}$ \\
163 A & $46,18 \mathrm{e}$ \\
Média geral & $84,02 \mathrm{f}$ \\
\hline
\end{tabular}

${ }^{(1)}$ Médias seguidas de letras iguais não diferem pelo teste $\mathrm{F}$, a $1 \%$ de probabilidade. Nas testemunhas, as médias seguidas de letras iguais não diferem pelo teste de Dunett, a $5 \%$ de probabilidade.
O padrão de resistência dos genitores BGH-2102, BGH-2117, BGH-2127, BGH-2130 e BGH-2343 foi o mesmo que o das testemunhas resistentes - o acesso BGH-6902 e as linhagens 133 A e 163 A -, uma vez que suas médias de AACPD não diferiram daquela das testemunhas. O genitor BGH-2332, também considerado resistente, não diferiu apenas da testemunha 163 A (Tabela 1).

Com esses resultados, confirma-se o potencial desses genitores para uso em programas de pré-melhoramento para resistência à requeima. Neste caso, os genitores são da mesma espécie cultivada ( $S$. lycopersicum), o que facilita a hibridação intraespecífica, o que não ocorre com o acesso BGH-6902, que é de outra espécie ( $S$. habrochaites), e com as linhagens derivadas (133 A e $163 \mathrm{~A}$ ), que, conforme Fiorini et al. (2010), apresentam diversos genes que controlam características agronomicamente indesejáveis.

Cabe destacar que a inclusão desses acessos em programas de melhoramento não prejudicaria demasiadamente as demais características de interesse agronômico, uma vez que não houve arraste gênico, o que pode ocorrer quando genitores silvestres são utilizados em cruzamentos (Marim et al., 2009).

Quanto aos híbridos, na maioria, não foi detectada diferença significativa em relação às testemunhas resistentes (BGH-6902, 133 A e 163 A), com exceção dos híbridos BGH-2332 x BGH-2102 e BGH-2117 x BGH-2102. O híbrido BGH-2117 x BGH-2102, com média de AACPD de 189,27 unidades de área (u.a.), diferiu apenas da testemunha mais resistente, a BGH-6902, enquanto o híbrido BGH-2332 x BGH-2102, com média de AACPD de 249,75 u.a., diferiu das três testemunhas resistentes (Tabela 1).

Observou-se a ocorrência de heterobeltiose entre os híbridos BGH-2127 x BGH-2117, com 61,14 u.a.; BGH-2130 x BGH-2127, com 58,68 u.a.; BGH-2127 x BGH-2102, com 55,96 u.a.; BGH-2127 x BGH-2343, com 52,39 u.a.; BGH-2130 x BGH-2102, com 48,43 u.a.; e BGH-2343 x BGH-2130, com 47,90 u.a. Estes resultados são indicativos de que a diversidade genética existente entre os genitores e as manifestações heteróticas exibidas por esses cruzamentos podem ser decorrentes da complementação gênica entre os locos que controlam a característica em estudo (Santos et al., 2011). A partir desses resultados, confirmou-se a predominância de efeitos de dominância no controle genético da requeima. Em programas de melhoramento, 
o sucesso da formação de populações segregantes tem como base a escolha dos genitores, e a capacidade combinatória, responsável pelo sucesso, resulta da presença de genes complementares (Lorencetti et al., 2005).

$\mathrm{O}$ efeito de tratamentos (genitores e híbridos) sobre a AACPD foi significativo. Na decomposição da soma de quadrados (SQ) de tratamentos em efeitos de capacidade geral e de capacidade específica de combinação (CGC e CEC, respectivamente), houve diferença apenas para a CGC (Tabela 2).

$\mathrm{O}$ resultado não significativo quanto à $\mathrm{CEC}$ é evidência da predominância de efeitos gênicos aditivos (Vivas et al., 2012a). O elevado valor do coeficiente de variação $(47,75 \%)$ para essa característica pode ter afetado o teste para a CEC. Entretanto, observouse maior SQCEC relativa à SQCGC, além de maior estimativa do componente quadrático para a CEC que para a CGC (Tabela 2), o que indica predominância de efeitos gênicos não aditivos no controle genético da característica AACPD e diversidade genética entre os genitores (Oliveira et al., 1998). O efeito da CGC

Tabela 2. Análise de variância para área abaixo da curva de progresso da doença (AACPD), para dialelo com seis genitores e 15 híbridos $\mathrm{F}_{1}{ }^{(1)}$.

\begin{tabular}{lcccc}
\hline $\begin{array}{l}\text { Fonte de } \\
\text { variação }\end{array}$ & GL & $\begin{array}{c}\text { Soma de } \\
\text { quadrados }\end{array}$ & $\begin{array}{c}\text { Quadrado } \\
\text { médio }\end{array}$ & $\begin{array}{c}\text { Componentes } \\
\text { quadráticos }\end{array}$ \\
\hline Tratamento & 20 & $183.214,50$ & $9.160,72^{* *}$ & - \\
CGC & 5 & $10.325,75$ & $20.065,15^{* *}$ & 705,22 \\
CEC & 15 & $82.888,75$ & $5.525,92^{\text {ns }}$ & 795,32 \\
\hline Resíduo & 40 & & 3139,95 & \\
\hline
\end{tabular}

${ }^{(1)} \mathrm{GL}$, grau de liberdade; CGC, capacidade geral de combinação; e CEC,

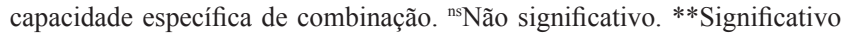
pelo teste $\mathrm{F}$, a $1 \%$ de probabilidade. é um indicador da superioridade de um genitor em relação aos demais (Rocha et al., 2014). Com base nas estimativas dos efeitos da CGC $\left(\hat{\mathrm{g}}_{\mathrm{i}}\right)$ para a AACPD (Tabela 3), verificou-se que os genitores BGH-2127, BGH-2130, BGH-2117 e BGH-2343 apresentaram as estimativas mais negativas, com valores de $-28,74$, $-23,66,-7,34$ e $-6,70$, respectivamente. Estes valores foram significativamente diferentes dos valores de $\hat{\mathrm{g}}_{\mathrm{i}} \mathrm{dos}$ outros genitores. No entanto, nos genitores BGH-2102 e BGH-2332, foram observadas estimativas positivas de $\hat{\mathrm{g}}_{\mathrm{i}}$ com valores de 17,60 e 48,84, respectivamente. Estimativas elevadas de $\hat{g}_{i}$ em valores absolutos ocorrem, em geral, para genitores cujas frequências dos alelos favoráveis são consistentemente maiores ou menores do que a média dos alelos favoráveis em todos os demais genitores, e também proporcionam informações sobre a concentração de genes de efeitos aditivos. Portanto, genitores com estimativas de CGC altas e positivas são os que mais contribuem para o aumento da expressão do caráter, enquanto aqueles com valores mais negativos contribuem para a redução de sua manifestação (Silva et al., 2000).

Os efeitos de $\hat{g}_{\mathrm{i}}$ são interpretados de acordo com o interesse do melhorista. Por se tratar de resistência, os genótipos que apresentam estimativas de $\hat{\mathrm{g}}_{\mathrm{i}}$ mais negativas seriam potencialmente superiores (Vivas et al., 2012b). A seleção para resistência à requeima é feita no sentido negativo, com menores valores de AACPD relacionados à maior resistência do indivíduo. Valores mais negativos de $\hat{\mathrm{g}}_{\mathrm{i}}$ devem ser buscados, por significarem que a média dos genitores utilizados em determinado cruzamento é menor que a média geral dos demais cruzamentos existentes no dialelo. Esses valores também são indicativos da importância dos genes de efeitos aditivos na variabilidade genética

Tabela 3. Estimativas das médias e dos efeitos da capacidade geral de combinação $\left(\hat{\mathrm{g}}_{\mathrm{i}}\right)$ para área abaixo da curva de progresso da doença (AACPD) de seis genitores $(\mathrm{G})$ e 15 híbridos $\mathrm{F}_{1}$ de tomateiro (Solanum lycopersicum).

\begin{tabular}{|c|c|c|c|c|c|c|c|}
\hline Genitores & BGH-2102 & BGH-2117 & BGH-2127 & BGH-2130 & BGH-2332 & BGH-2343 & $\hat{g}_{\mathrm{i}}$ \\
\hline BGH-2102 & 86,89 & 189,27 & 55,96 & 48,43 & 249,75 & 120,24 & 17,60 \\
\hline BGH-2117 & & 64,36 & 61,13 & 88,90 & 78,52 & 91,31 & $-7,34$ \\
\hline BGH-2127 & & & 79,02 & 58,68 & 80,53 & 52,39 & $-28,74$ \\
\hline BGH-2130 & & & & 61,61 & 140,20 & 47,90 & $-23,66$ \\
\hline BGH-2332 & & & & & 199,36 & 139,67 & 48,84 \\
\hline BGH-2343 & & & & & & 95,75 & $-6,70$ \\
\hline Desvio-padrão (Gi) & & & & & & & 10,44 \\
\hline Desvio-padrão (Gi - Gj) & & & & & & & 16,18 \\
\hline
\end{tabular}


dos materiais utilizados (Pádua et al., 2010). Assim, os genitores BGH-2127, BGH-2130, BGH-2117 e BGH-2343 são, nesta ordem, superiores em relação à frequência de alelos de resistência à requeima. Genitores com maiores valores de CGC podem ser recomendados para programas de melhoramento intrapopulacional (Oliboni et al., 2013), para a obtenção de linhagens superiores quanto à resistência à requeima (Krause et al., 2012). Entretanto, essas informações devem ser complementadas com estimativas de CEC, para a escolha dos genótipos mais divergentes, já que os maiores valores estão associados aos genótipos mais dissimilares nas frequências dos genes com dominância (Rocha et al., 2014).

Foram observadas estimativas de $\hat{\mathrm{s}}_{\mathrm{ii}}$ com valores positivos para os genitores BGH-2127, BGH-2130, BGH-2332 e BGH-2343, e negativos para os genitores BGH-2102 e BGH-2117 (Tabela 4). Segundo Cruz \& Vencovsky (1989), valores positivos e negativos de $\hat{s}_{\mathrm{ii}}$ são indicativos da existência de desvios de dominância bidirecional no controle do caráter em questão. Os autores ainda ressaltam que valores positivos de $\hat{\mathrm{S}}_{\mathrm{ii}}$ são indicativos de desvios de dominância negativos no controle genético do caráter, e vice-versa para os valores negativos de $\hat{\mathrm{s}}_{\mathrm{ii}}$.
Com base nos valores de $\hat{\mathrm{s}}_{\mathrm{ii}}$ dos genitores BGH-2117, BGH-2127, BGH-2130 e BGH-2343, constatouse que, com exceção do primeiro genitor, os demais apresentam valores de $\hat{s}_{\mathrm{ii}}$ positivos, o que indica maior frequência de alelos favoráveis com desvios de dominância negativos. O genitor BGH-2117 foi divergente em relação aos três anteriores, pois apresenta valor negativo de $\hat{s}_{\mathrm{ii}}$, o que mostra maior frequência de alelos favoráveis com desvios de dominância positivos.

Além disso, observaram-se estimativas de heterose percentual com seis valores positivos e nove negativos (Tabela 5), o que confirma os desvios de dominância bidirecional existentes no controle genético da requeima e a predominância de desvios negativos.

A partir da CEC dos três genitores que apresentam desvios de dominância negativos, isto é, BGH-2127, BGH-2130 e BGH-2343 (Tabela 4), pode-se escolher aqueles mais divergentes em relação ao genitor BGH-2127, de maior frequência de alelos favoráveis $\left(\hat{\mathrm{g}}_{\mathrm{i}}=-28,72\right)$. A CEC do cruzamento entre os genitores BGH-2127 x BGH-2130 foi positiva e igual a 11,56, enquanto a CEC do cruzamento entre os genitores BGH-2127 x BGH-2343 foi negativa e igual $-11,69$, $\mathrm{o}$ que indica maior divergência entre esses genitores. Desse modo, os genitores BGH-2127, BGH-2343 e

Tabela 4. Estimativas dos efeitos da capacidade específica de combinação $\left(\hat{\mathrm{s}}_{\mathrm{ii}}\right.$ e $\left.\hat{\mathrm{s}}_{\mathrm{ij}}\right)$ para área abaixo da curva de progresso da doença (AACPD) de seis genitores e 15 combinações híbridas $\mathrm{F}_{1}$ de tomateiro (Solanum lycopersicum), além de desvio-padrão dos efeitos de dois $\mathrm{F}_{1}$ com e sem genitor comum.

\begin{tabular}{|c|c|c|c|c|c|c|}
\hline Genitores & BGH-2102 & BGH-2117 & BGH-2127 & BGH-2130 & BGH-2332 & BGH-2343 \\
\hline BGH-2102 & $-47,83$ & 79,49 & $-32,42$ & $-45,02$ & 83,78 & 9,82 \\
\hline BGH-2117 & & $-20,46$ & $-2,31$ & 20,39 & $-62,50$ & 5,85 \\
\hline BGH-2127 & & & 36,97 & 11,56 & $-39,09$ & $-11,69$ \\
\hline BGH-2130 & & & & 9,42 & 15,50 & $-21,25$ \\
\hline BGH-2332 & & & & & 2,15 & $-1,99$ \\
\hline BGH-2343 & & & & & & 9,63 \\
\hline Desvio-padrão $\left(\hat{\mathrm{s}}_{\mathrm{ii}}\right)$ & & 23,68 & & & & \\
\hline Desvio-padrão $\left(\hat{\mathrm{s}}_{\mathrm{ii}}-\hat{\mathrm{s}}_{\mathrm{ij}}\right)$ & & 32,35 & & & & \\
\hline
\end{tabular}

Tabela 5. Estimativas da heterose percentual para área abaixo da curva de progresso da doença (AACPD) de 15 combinações híbridas $\mathrm{F}_{1}$ de tomateiro (Solanum lycopersicum).

\begin{tabular}{|c|c|c|c|c|c|c|}
\hline Genitores & BGH-2102 & BGH-2117 & BGH-2127 & BGH-2130 & BGH-2332 & BGH-2343 \\
\hline BGH-2102 & - & 150,26 & $-32,54$ & $-34,77$ & 74,50 & 31,67 \\
\hline BGH-2117 & & - & $-14,74$ & 41,13 & $-40,45$ & 14,06 \\
\hline BGH-2127 & & & - & $-16,55$ & $-42,17$ & $-40,05$ \\
\hline BGH-2130 & & & & - & 7,44 & $-39,12$ \\
\hline BGH-2332 & & & & & - & $-5,34$ \\
\hline BGH-2343 & & & & & & - \\
\hline
\end{tabular}

Pesq. agropec. bras., Brasília, v.51, n.1, p.27-34, jan. 2016

DOI: 10.1590/S0100-204X2016000100004 
BGH-2117 apresentam potencial para serem incluídos em programas de melhoramento intrapopulacional, para obtenção de linhagens superiores quanto à resistência à requeima.

\section{Conclusão}

Os acessos BGH-2117, BGH-2127 e BGH-2343 apresentam maior frequência de alelos favoráveis e divergentes, e são adequados ao uso em cruzamentos para o pré-melhoramento quanto à resistência à requeima.

\section{Agradecimentos}

À Coordenação de Aperfeiçoamento de Pessoal de Nível Superior (Capes), ao Conselho Nacional de Desenvolvimento Científico e Tecnológico $(\mathrm{CNPq})$ e à Fundação de Amparo à Pesquisa do Estado de Minas Gerais (Fapemig), pela concessão de bolsas e pelo apoio financeiro.

\section{Referências}

ABREU, F.B.; SILVA, D.J.H. das; CRUZ, C.D.; MIZUBUTI, E.S.G. Inheritance of resistance to Phytophthora infestans (Peronosporales, Pythiaceae) in a new source of resistance in tomato (Solanum sp. (formerly Lycopersicon sp.), Solanales, Solanaceae). Genetics and Molecular Biology, v.31, p.493-497, 2008. DOI: $10.1590 / \mathrm{S} 1415-47572008000300016$.

ADALID, A.M.; ROSELLÓ, S.; VALCÁRCEL, M.; NUEZ, F. Analysis of the genetic control of $\beta$-carotene and L-ascorbic acid accumulation in an orange-brownish wild cherry tomato accession. Euphytica, v.184, p.251-263, 2012. DOI: 10.1007/ s10681-011-0584-x.

CORREAA, F.M.; BUENO FILHO, J.S.S.; CARMO, M.G.F. Comparison of three diagrammatic keys for the quantification of late blight in tomato leaves. Plant Pathology, v.58, p.1128-1133, 2009. DOI: $10.1111 /$ j.1365-3059.2009.02140.x.

CRUZ C.D.; REGAZZI, A.J.; CARNEIRO, P.C.S. Modelos biométricos aplicados ao melhoramento genético. Viçosa: UFV, 2012.514 p.

CRUZ, C.D.; VENCOVSKY, R. Comparação de alguns métodos de análise dialélica. Revista Brasileira de Genética, v.12, p.425-438, 1989.

ELSAYED, A.Y.A.M.; DA SILVA HENRIQUES, D.; MIZUBUTI, E.S.G.; CARNEIRO, PC.P. Combing the monogenic and polygenic resistant genes to late blight in tomato. Journal of Plant Breeding and Crop Science, v.3, p.251-259, 2011.

FIORINI, C.V.A.; SILVA, D.J.H. da; MIZUBUTI, E.S.G.; BARROS, J. de S.; SILVA, L.J. da; MILAGRES, C.; ZAPAROLI, M.R. Caracterização de linhagens de tomateiro originadas de cruzamento interespecífico quanto à resistência à requeima. Horticultura Brasileira, v.28, p.197-202, 2010. DOI: 10.1590/ S0102-05362010000200010.

FOOLAD, M.R.; SULLENBERGER, M.T.; OHLSON, E.W.; GUGINO, B.K. Response of accessions within tomato wild species, Solanum pimpinellifolium to late blight. Plant Breeding, v.133, p.401-411, 2014. DOI: 10.1111/pbr.12172.

GRIFFING, B. Concept of general and specific combining ability in relation to diallel crossing systems. Australian Journal of Biological Sciences, v.9, p.463-493, 1956. DOI: 10.1071/ BI9560463.

GUIMARÃES, M.A.; CALIMAM, F.R.B.; SILVA, D.J.H.; MARIM, B.G.; SOUZA, J.B. Tratos culturais do tomateiro. In: SILVA, D.J.H.; VALE, F.X.R. do. (Ed.). Tomate: tecnologia de produção. Visconde do Rio Branco: Suprema, 2007. p.85-99.

KRAUSE, W.; RODRIGUES, R.; LEAL, N.R. Capacidade combinatória para características agronômicas em feijão-de-vagem. Revista Ciência Agronômica, v.43, p.522-531, 2012. DOI: 10.1590/S1806-66902012000300015.

LORENCETTI, C.; CARVALHO, F.I.F. de; BENIN, G.; MARCHIORO, V.; OLIVEIRA, A.C. de; SILVA, J.A.G. da; HARTWIG, I.; SCHMIDT, D.A.M.; VALÉRIO, I.P. Capacidade combinatória e heterose em cruzamento dialélico de aveia (Avena sativa L.). Revista Brasileira Agrociência, v.11, p.143-148, 2005.

MADDEN, L.V.; HUGHES, G.; BOSCH, F. van den. The study of plant disease epidemics. St. Paul: APS Press, 2007. 432p.

MARIM, B.G.; SILVA, D.J.H. da; CARNEIRO, P.C.S.; MIRANDA, G.V.; MATTEDI, A.P.; CALIMAN, F.R.B. Variabilidade genética e importância relativa de caracteres em acessos de germoplasma de tomateiro. Pesquisa Agropecuária Brasileira, v.44, p.1283-1290, 2009. DOI: 10.1590/S0100-204X2009001000011.

MIRANDA, B.E.C. de; SUASSUNA, N.D.; REIS, A. Mating type, mefenoxam sensitivity, and pathotype diversity in Phytophthora infestans isolates from tomato in Brazil. Pesquisa Agropecuária Brasileira, v.45, p.671-679, 2010. DOI: 10.1590/ S0100-204X2010000700006.

NICK, C.; LAURINDO, B.S.; ALMEIDA, V. de S.; FREITAS, R.D. de; AGUILERA, J.G.; SILVA, E.C.F. da; CRUZ, C.D.; SILVA, D.J.H. da. Seleção simultânea para qualidade do fruto e resistência à requeima em progênies de tomateiro. Pesquisa Agropecuária Brasileira, v.48, p.59-65, 2013. DOI: 10.1590/ S0100-204X2013000100008.

NOWICKI, M.; FOOLAD, M.R.; NOWAKOWSKA, M.; KOZIK, E.U. Potato and tomato late blight caused by Phytophthora infestans: an overview of pathology and resistance breeding. Plant Disease, v.96, p.4-17, 2012. DOI: 10.1094/PDIS-05-11-0458.

NOWICKI, M.; KOZIK, E.U.; FOOLAD, M.R. Late blight of tomato. In: VARSHNEY, R.; TUBEROSA, R. (Ed.). Translational genomics for crop breeding. New York: J. Wiley \& Sons, 2013. p.241-265. DOI: 10.1002/9781118728475.ch13.

NUTTER, J.R.F.W. Disease severity assessment training. In: FRANCL, L.J.; NEHER, D.A. Exercises in plant disease epidemiology. St. Paul: APS Press, 1997, p.1-7. 
OLIBONI, R.; FARIA, M.V.; NEUMANN, M.; RESENDE, J.T.V.; BATTISTELLI, G.M.; TEGONI, R.G.; OLIBONI, D.F. Análise dialélica na avaliação do potencial de híbridos de milho para a geração de populações-base para obtenção de linhagens. Semina: Ciências Agrárias, v.34, p.7-17, 2013. DOI: 10.5433/1679-0359.2013v34n1p7.

OLIVEIRA, V.R.; CASALI, V.W.D.; CRUZ, C.D.; PEREIRA, P.R.G.; SCAPIM, C.A. Capacidade de combinação entre linhagens de pimentão diferindo na tolerância ao baixo teor de fósforo no solo. Bragantia, v.57, p.203-214, 1998. DOI: 10.1590/ S0006-87051998000200002.

PÁDUA, T.R.P. de; GOMES, L.A.A.; MALUF, W.R.; CARVALHO FILHO, J.L.S. de; GONÇALVES NETO, C.G.; ANDRADE, M.C. Capacidade combinatória de híbridos de tomateiro de crescimento determinado, resistentes a Begomovirus e Tospovirus. Pesquisa Agropecuária Brasileira, v.45, p.818-825, 2010. DOI: 10.1590/ S0100-204X2010000800007.

ROCHA, F. da; STINGHEN, J.C.; GEMELI, M.S.; COIMBRA, J.L.M.; GUIDOLIN, A.F. Análise dialélica como ferramenta na seleção de genitores em feijão. Revista Ciência Agronômica, v.45, p.74-81, 2014. DOI: 10.1590/S1806-66902014000100010.

SANTOS, F.F.B. dos; RIBEIRO, A.; SIQUEIRA, W.J.; MELO, A.M.T.de. Desempenho agronômico de híbridos $\mathrm{F}_{1}$ de tomate de mesa. Horticultura Brasileira, v.29, p.304-310, 2011. DOI: 10.1590/S0102-05362011000300008.

SILVA, S.A.G. e; MORAIS, O.P. de; RAVA, C.A.; COSTA, J.G.C. da. Método generalizado de análise de dialelos desbalanceados. Pesquisa Agropecuária Brasileira, v.35, p.1999-2005, 2000. DOI: $10.1590 /$ S0100-204X2000001000011.

VIVAS, M.; SILVEIRA, S.F. da; CARDOSO, D.L.; PEREIRA, M.G.; SANTOS, P.H.D. dos; FERREGUETTI, G.A. Capacidade combinatória e heterose para resistência a pinta-preta em mamoeiro por meio de análise dialélica. Tropical Plant Pathology, v.37, p.326-332, 2012a. DOI: 10.1590/S1982-56762012000500004.

VIVAS, M.; SILVEIRA, S.F. da; CARDOSO, D.L.; PEREIRA, M.G.; VIVAS, J.M.S; FERREGUETTI, G.A. Capacidade combinatória em mamoeiro para resistência a oídio. Bragantia, v.71, p.455-459, 2012b. DOI: 10.1590/S0006-87052012000400001.

Recebido em 22 de julho de 2015 e aprovado em 4 de dezembro de 2015 